\title{
Mapeamento dos Anfíbios e Répteis ameaçados de extinção no Estado do Rio Grande do Sul, Brasil
}

\author{
Maurício Rizzatti $^{(\mathrm{a})}$, Pedro Leonardo Cezar Spode ${ }^{(\mathrm{b})}$, Iago Turba Costa ${ }^{(\mathrm{c})}$, Roberto Cassol $^{(\mathrm{d})}$ \\ (a) Mestrando em Geografia, Universidade Federal de Santa Maria, geo.mauricio.rizzatti@gmail.com \\ (b) Acadêmico do curso de Geografia, Universidade Federal de Santa Maria, pedrospode@ gmail.com \\ (c) Acadêmico do curso de Geografia, Universidade Federal de Santa Maria, iagoturba@ hotmail.com \\ (d) Prof. Dr. do Departamento de Geociências, Universidade Federal de Santa Maria, rtocassol@gmail.com
}

\section{EIXO: BIOGEOGRAFIA, MANEJO DE ÁREAS NATURAIS E PROTEGIDAS: CONSERVAÇÃO DA BIODIVERSIDADE}

\begin{abstract}
Resumo:
A extinção das mais variadas espécies em nível local e global, é constante. Frente a isso, a discussão se torna importante no sentido de revelar o nível dos impactos. Diante disso, tem-se como objetivo deste trabalho espacializar a localização dos anfíbios e répteis ameaçados de extinção no estado do Rio Grande do Sul (RS) conforme a lista apresentada pela Fundação Zoobotânica do RS. De acordo com a categoria de risco dos anfíbios e répteis, é possível verificar uma predominância da categoria Em Perigo (EN), fato que demonstra um descuido com os ecossistemas. Analisando os mapas, percebe-se que as espécies possuem um padrão de distribuição, isto é, uma concentração no bioma da Mata Atlântica e pouquíssimas espécies no bioma Pampa, segundo a pesquisa realizada.
\end{abstract}

Palavras chave: Mapas; Lista Vermelha da IUCN; Fundação Zoobotânica do RS; QGIS.

\section{Introdução}

A extinção de espécies, em nível local e global, é interrupta. A discussão se torna fundamental no sentido de revelar os impactos causados ao espaço geográfico, principalmente, pela supressão da vegetação, e consequentemente, a destruição dos ambientes naturais e seres vivos, que tem sido descaracterizado de forma veloz pela ação antrópica (PONTES, 2017, p. 15).

O Brasil é conhecido por sua dimensão territorial, na qual, abrange aproximadamente a metade de toda a América Latina, que o torna o quinto maior país do mundo em extensão territorial, assim como, é um dos países que mais apresentam biodiversidade, abrigando cerca de 13,2\% da biota mundial (LEWINSOHN; PRADO, 2006). Desse modo, não é somente a área territorial que possui destaque, mas também, a grande variedade de espécies animais e vegetais presentes, que atualmente, frente a exploração desenfreada dos recursos naturais, encontra-se em eminente perigo. Segundo Machado et al (2008, p.39) "a principal causa da perda de grandes áreas e, por conseguinte, de espécies [...] e ecossistemas e serviços associados, derivase do modelo econômico e de ocupação territorial pela população humana". 
Nesse sentido Rizzatti et al. (2016) ressaltam:

[...] a Mata Atlântica é o bioma brasileiro mais alterado. Essa degradação vem desde a época colonial, pela extração predatória do Pau-Brasil, e em seguida com o cultivo de cana-de-açúcar, próximo ao litoral brasileiro. Também, fez-se presente pelo plantio do café na região sudeste no século XIX e no século XX pela urbanização brasileira, principalmente com a localização de algumas capitais estarem situadas no bioma da Mata Atlântica. É possível observar que o modo de ocupação do território brasileiro deuse do litoral ao interior do país, justificando assim a supressão da vegetação, caracterizando a Mata Atlântica como um dos hotspots de biodiversidade brasileiro (RIZZATTI et al. 2016, p. 3).

No estado do Rio Grande do Sul, outro bioma presente, além da Mata Atlântica, é o Pampa, que abrange cerca de $63 \%$ do estado, peculiarmente é o único bioma brasileiro restrito a um único estado (IBGE, 2004). Todavia, a conservação de sua biota é bastante ameaçada, principalmente pela questão da agricultura extensiva e pela silvicultura, bem como pela introdução de espécies exóticas. Desse modo, Pillar et al (2009) aborda que:

Nas últimas décadas, cerca de metade da superfície originalmente coberta com os Campos no estado do Rio Grande do Sul foi transformada em outros tipos de cobertura vegetal. Esse processo aconteceu sem que limites tenham sido efetivamente estabelecidos e aplicados nem pelo poder público nem pela sociedade. A legislação ambiental a respeito é ainda precária e negligenciada, algumas políticas públicas têm estimulado a conversão e os Campos estão pobremente representados nos sistemas de áreas protegidas (PILLAR et al, 2009, p. 5).

Nesse sentido, compreendendo a natureza como um todo, em sua vasta riqueza natural, sobretudo no Brasil, onde a biodiversidade é abundante, se faz necessário discutir sobre a extinção de espécies. A atividade antrópica faz com que as espécies de um determinado ecossistema seja diminuída ou até extinta, de forma que muitas vezes não haja um registro de certas espécies. De forma a se pensar a uma condição de protegê-las, a União Internacional para a Conservação da Natureza (IUCN), elabora listas vermelhas apontando espécies que estão em perigo de extinção, apresentando a importância e buscando aumentar o amparo a essas espécies.

Em relação à necessidade de preservação existem unidades de conservação que buscam resguardar a condição básica de fauna e flora para a existência de espécies, tentando impedir o desaparecimento de sua condição natural e possibilitando um equilíbrio ecológico entre as mesmas. Assim, a preocupação em desenvolver esta problemática tem grande significância, na tentativa de frear a degradação dos ecossistemas. Com base no exposto, algumas instituições elaboram estudos a fim de elencar os animais que necessitam uma maior atenção. Destes estudos surgem as Listas Vermelhas da IUCN.

Segundo a IUCN (2001) 
The IUCN Red List Categories and Criteria are intended to be an easily and widely understood system for classifying species at high risk of global extinction. The general aim of the system is to provide an explicit, objective framework for the classification of the broadest range of species according to their extinction risk. However, while the Red List may focus attention on those taxa at the highest risk, it is not the sole means of setting priorities for conservation measures for their protection (IUCN, 2001, p. 1). ${ }^{1}$

As espécies são classificadas em nove classes, definidos através de critérios que incluem a taxa de declínio da população (número de indivíduos por espécies, tamanho e distribuição da população, além da área de distribuição geográfica e grau de fragmentação), que abrangem desde a categoria de animais já Extintos (EX) até Pouco Preocupante (LC), que é a categoria de menor risco, conforme exposto na figura 1. Deste modo, a Lista Vermelha da IUCN obedece a critérios de forma a poder avaliar o risco de extinção para milhares de espécies e subespécies em todo mundo.

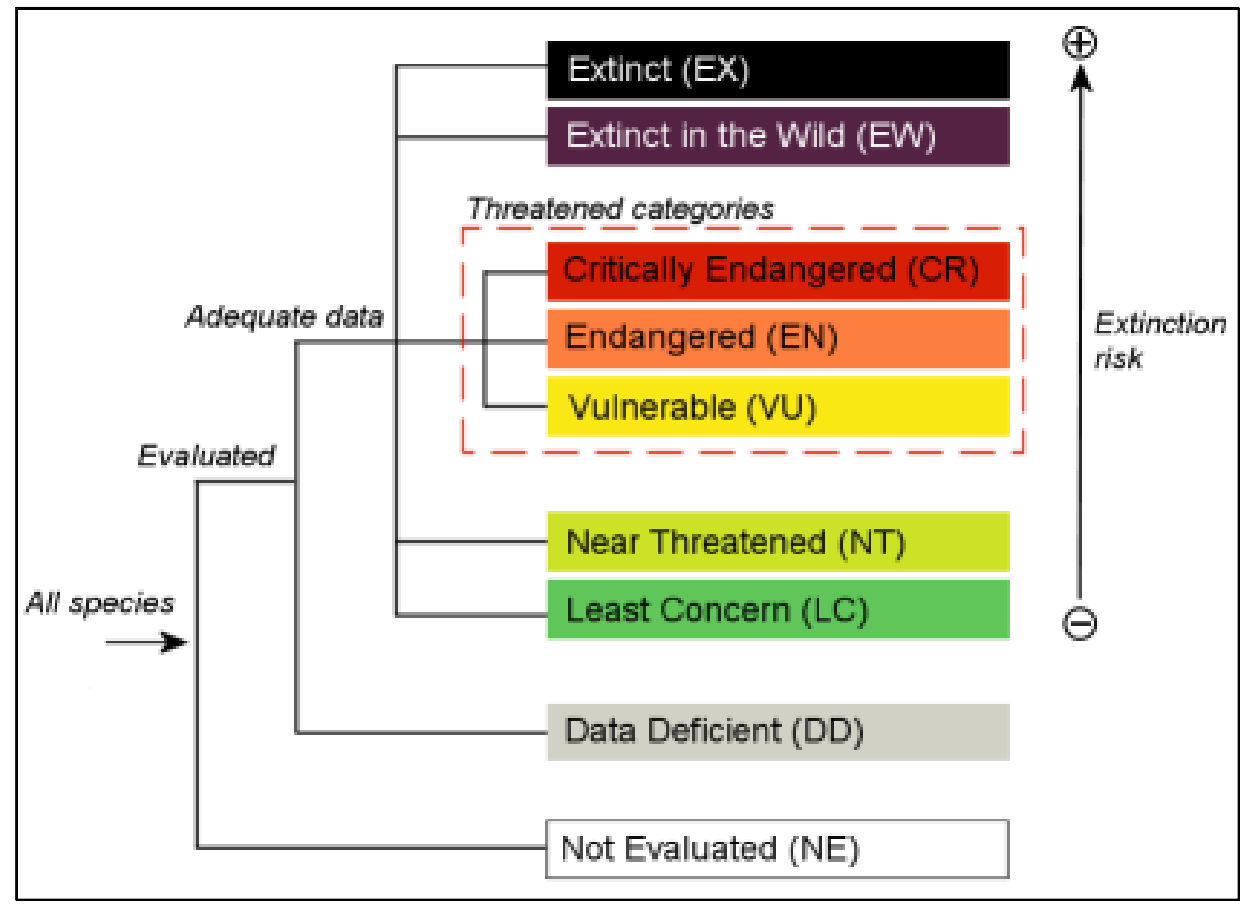

Figura 1 - Relações entre as categorias de risco da IUCN.

Fonte: IUCN, 2001

Existe uma "subcategoria" que as espécies são ameaçadas de extinção, onde são classificadas em Vulneráveis (VU), Em Perigo (EN) e Criticamente em Perigo (CR), conforme caracterizadas na figura 2, no qual é objeto de estudo desse trabalho, que analisa as classes de anfíbios e répteis..

\footnotetext{
${ }^{1}$ [Nota de tradutor] As Categorias e Critérios da Lista Vermelha da IUCN pretendem ser um sistema fácil e amplamente compreendido para a classificação de espécies em alto risco de extinção global. O objetivo é fornecer um quadro explícito para a classificação da mais ampla gama de espécies de acordo com o seu risco de extinção. No entanto, embora a Lista Vermelha possa concentrar a atenção nos taxa de maior risco, não é o único meio de estabelecer prioridades para medidas de conservação para sua proteção.
} 


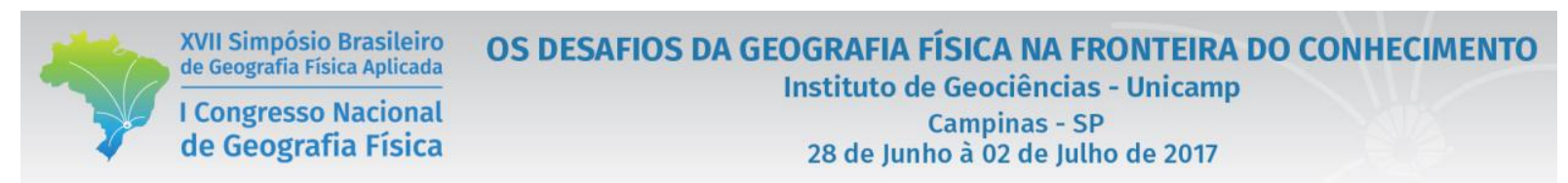

\begin{tabular}{|c|c|}
\hline Categoria de Risco & Características \\
\hline VU-Vulnerável & $\begin{array}{l}\text { Vulnerável (VU) é a categoria "menos preocupante", dentro do grupo } \\
\text { das espécies ameaçadas, mas possui um risco elevado de extinção da } \\
\text { natureza. Entretanto, para diminuir a seriedade das espécies que se } \\
\text { encontram como VU, é necessário que as ameaças se reduzam, para } \\
\text { que ocorra o aumento da reprodução. }\end{array}$ \\
\hline EN - Em Perigo & $\begin{array}{l}\text { É o segundo estado de conservação mais grave da natureza, seguindo } \\
\text { os critérios de } \mathrm{A} \text { ao } \mathrm{E} \text {, da lista vermelha da IUCN, onde estes apontam } \\
\text { sobre a diminuição da distribuição geográfica, bem como do número } \\
\text { de indivíduos de cada espécie. }\end{array}$ \\
\hline $\begin{array}{c}\text { CR - Criticamente } \\
\text { em Perigo }\end{array}$ & $\begin{array}{l}\text { Por último a categoria Criticamente em Perigo (CR), é a mais grave para } \\
\text { a conservação da natureza, principalmente para espécies selvagens. Os } \\
\text { indivíduos que se enquadram nessa categoria merecem o máximo de } \\
\text { atenção, pois a categoria posterior seria a da Extinção da Natureza } \\
\text { (EW). }\end{array}$ \\
\hline
\end{tabular}

Figura 2 - Categorias de risco das espécies ameaçadas de extinção

Organização: Os autores

Para se considerar uma espécie extinta a IUCN realiza pesquisas para comprovar realmente a extinção das mesmas, portanto, é possível que espécies já extintas, ainda estejam classificadas como CR.

Desta forma, o presente trabalho tem como objetivo representar espacialmente a localização dos anfíbios e répteis ameaçados de extinção no estado do Rio Grande do Sul, segundo a lista da fundação Zoobotânica do Rio Grande do Sul (FZB/RS), assim como, quantificar as categorias de risco (Vulnerável, Em Perigo e Criticamente em Perigo) dos anfíbios e répteis, conforme apresentadas pela FZB/RS.

\section{Materiais e métodos}

A primeira etapa da pesquisa consistiu em uma revisão bibliográfica dos critérios utilizados pela IUCN para compreender como ocorre a classificação das espécies. Além disso, teve-se acesso a lista dos anfíbios e répteis ameaçados de extinção no estado do Rio Grande do Sul, com base na FZB/RS que elabora seus estudos utilizando os critérios propostos pela IUCN, tendo assim como objetivo principal informar sobre a urgência das medidas de conservação para o público e para os gestores públicos, na tentativa de preservação e manutenção das espécies com a redução das extinções.

Para a elaboração dos mapas, em um primeiro momento, foram revisados artigos científicos e sites governamentais para se encontrar uma provável localização das espécies de répteis e anfíbios, que foram classificados como ameaçados de extinção, baseados na lista da FZB/RS (FZB/RS, 2014), no estado do Rio Grande do Sul. Posteriormente, todas as espécies foram agrupadas em quadros (dos répteis e anfíbios), com informações referentes à distribuição geográfica (localização) encontrada através da 
pesquisa realizada (e autor da referida pesquisa). Além disso, traz informações sobre classe, ordem e família de cada uma das espécies.

Após a sistematização dos quadros, realizou-se a confecção dos mapas dos anfíbios e répteis ameaçados de extinção, baseada na localização encontrada durante a pesquisa. Ressalta-se que o objetivo é encontrar ao menos uma amostra da distribuição geográfica para a espécie. Entretanto, alguns répteis e anfíbios tiveram mais de uma representação no mapa, visto que, alguns artigos apresentaram várias localizações, e, portanto, algumas espécies estão situadas em dois ou mais municípios.

A produção dos mapas foi realizada no software QGIS 2.14.9, utilizando a malha digital de municípios do Instituto Brasileiro de Geografia e Estatística (IBGE, 2010) e a base cartográfica vetorial contínua do Rio Grande do Sul (HASENACK, H.; WEBER, E., 2010), que serviu para auxiliar a localização das espécies. Os shapefiles referentes aos biomas foram adquiridos do Ministério do Meio Ambiente (ROMA, 2007). Por fim, fez-se a interpretação e sobreposição dos mapas para verificar se ocorria alguma concentração das espécies de anfíbios e répteis.

\section{Resultados e discussões}

Com o acesso a lista dos animais ameaçados de extinção do estado do Rio Grande do Sul e consulta em trabalhos científicos, realizou-se um mapeamento para as espécies de anfíbios e répteis que constam na listagem. Deste modo, a figura 3 ilustra o mapa dos anfíbios ameaçados de extinção no estado do Rio Grande do Sul.

Analisando o mapa da figura 3, é possível visualizar uma concentração das espécies no litoral norte gaúcho e nos Campos de Cima da Serra. No município de Torres, localizado no litoral norte, já houve registro de Haddadus binotatus (popularmente conhecida como rã-das-matas), localizada no Parque Estadual de Itapeva, e Melanophryniscus dorsalis (sapinho-de-barriga-vermelha), sendo essa, também encontrada em Cidreira e Tramandaí. A espécie Melanophryniscus macrogranulosus (sapinho-narigudode-barriga-vermelha) fora encontrada em Dom Pedro de Alcântara (Morro da Gruta) e Maquiné (Barra do Ouro), conforme apontado nos estudos de Escobar, et al. (2004). No último município, identificou-se Thoropa saxatilis (rã-das-pedras), na Cascata da Forqueta.

Tratando-se dos Campos de Cima da Serra, Itapotihyla langsdorffii (perereca) foi localizada no município de Itati, na Reserva Biológica da Mata Paludosa. A referida espécie deve ser monitorada, pois encontra-se na categoria mais grave para a conservação da natureza (Criticamente em Perigo - CR). Outra espécie de 


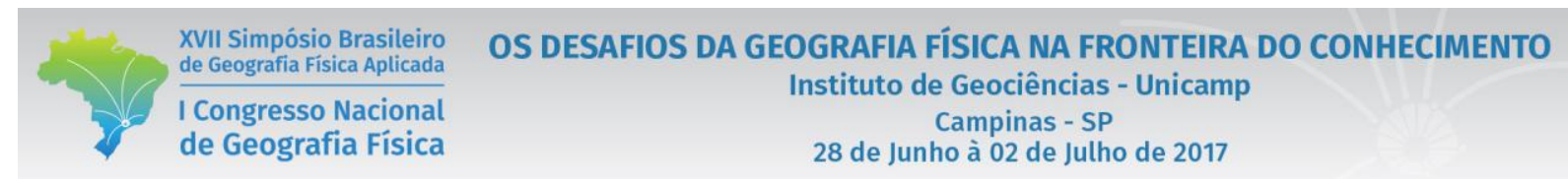

perereca (Phyllomedusa distincta) foi localizada em Dom Pedro de Alcântara, São Francisco de Paula e

Terra de Areia, conforme Lema, et al. (2011).

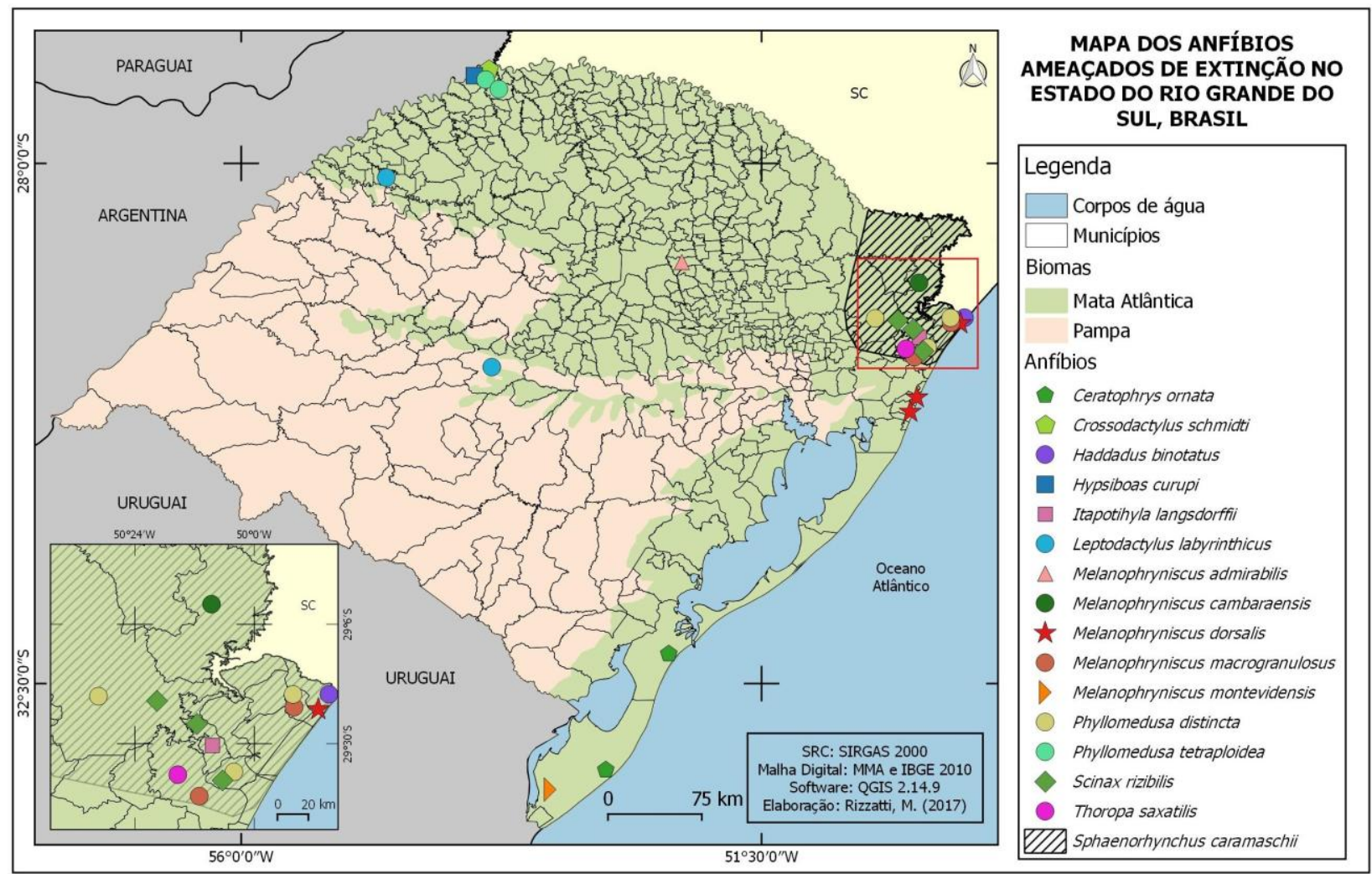

Figura 3 - Mapa dos anfíbios ameaçados de extinção no estado do Rio Grande do Sul Elaboração: RIZZATTI, 2017.

Além disso, Scinax rizibilis (perereca) foi identificada em Terra de Areia, Itati e São Francisco de Paula (LEMA, et al. 2011). No município de Cambará do Sul, encontrou-se Melanophryniscus cambaraensis (sapinho-verde-de-barriga-vermelha), que habita locais de elevada altitude. A Sphaenorhynchus caramaschii (perereca-verde-do-brejo), não fora encontrada uma localização específica (município), todavia, nos estudos de Fonte, et al. (2008), aponta que o habitat natural da referida espécie é no litoral norte e Campos de Cima da Serra, sendo endêmicos da região sul do país. Nesse sentido, a pererecaverde-do-brejo possui uma representação poligonal no mapa da figura 3.

Tratando-se do litoral sul, foram encontradas duas espécies de sapos em Santa Vitória do Palmar, a Melanophryniscus montevidensis (sapinho-de-barriga-vermelha-uruguaio) e Ceratophrys ornata (sapo-dechifres ou sapo-boi), também encontrado nas dunas costeiras de Rio Grande.

Já Melanophryniscus admirabilis (sapinho-de-barriga-vermelha) fora identificada no Vale do rio Taquari, no município de Arvorezinha. No noroeste do estado, há duas espécies de pererecas (Hypsiboas curupi e Phyllomedusa tetraploidea) e uma rã (Crossodactylus schmidti), todas encontradas no Parque Estadual do 


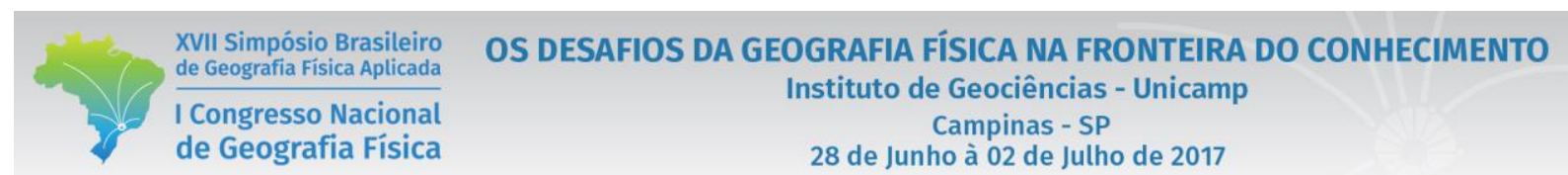

Turvo, em Derrubadas. Por fim, a Leptodactylus labyrinthicus (rã-pimenta) foi encontrada na região central do estado, no município de Santa Maria. Já em Cerro Largo foi achada morta uma fêmea gravida da referida espécie.

Conforme já mencionado, as localizações encontradas foram sistematizadas em quadros. Deste modo, a figura 4, explana informações referentes aos anfíbios, isto é, nome científico, classe, ordem, família, categoria de risco em que cada espécie se enquadra, município/região onde se localiza, além do autor que apresentou o estudo com a localização.

\begin{tabular}{|c|c|c|c|c|c|c|}
\hline Nome & Classe & Ordem & Família & Categoria & Município & Autor \\
\hline $\begin{array}{c}\text { Ceratophrys } \\
\text { ornata }\end{array}$ & Amphibia & Anura & Ceratophrydae & $\mathrm{CR}$ & $\begin{array}{l}\text { Santa Vitória } \\
\text { do Palmar e } \\
\text { Rio Grande }\end{array}$ & $\begin{array}{l}\text { Gayer. et } \\
\text { al. } 1988\end{array}$ \\
\hline $\begin{array}{c}\text { Crossodactylus } \\
\text { schmidti }\end{array}$ & Amphibia & Anura & Hylodidae & EN & Derrubadas & $\begin{array}{c}\text { Caldart. et } \\
\text { al. } 2013\end{array}$ \\
\hline $\begin{array}{l}\text { Haddadus } \\
\text { binotatus }\end{array}$ & Amphibia & Anura & Craugastoridae & EN & Torres & $\begin{array}{c}\text { Coco. et al. } \\
2014\end{array}$ \\
\hline Hypsiboas curupi & Amphibia & Anura & Hylidae & EN & Derrubadas & $\begin{array}{c}\text { Iop. et al. } \\
2009\end{array}$ \\
\hline $\begin{array}{l}\text { Itapotihyla } \\
\text { langsdorffii }\end{array}$ & Amphibia & Anura & Hylidae & $\mathrm{CR}$ & Itati & $\begin{array}{l}\text { Lingnau.et } \\
\text { al. } 2005\end{array}$ \\
\hline $\begin{array}{l}\text { Leptodactylus } \\
\text { labyrinthicus }\end{array}$ & Amphibia & Anura & Leptodactylidae & $\mathrm{CR}$ & $\begin{array}{c}\text { Santa Maria } \\
\text { e Cerro } \\
\text { Largo* }\end{array}$ & $\begin{array}{l}\text { Santos. et } \\
\text { al. } 2006\end{array}$ \\
\hline $\begin{array}{c}\text { Melanophryniscus } \\
\text { admirabilis }\end{array}$ & Amphibia & Anura & Bufonidae & $\mathrm{CR}$ & Arvorezinha & $\begin{array}{c}\text { Lema, } \\
2011\end{array}$ \\
\hline $\begin{array}{c}\text { Melanophryniscus } \\
\text { cambaraensis }\end{array}$ & Amphibia & Anura & Bufonidae & $\mathrm{VU}$ & $\begin{array}{c}\text { Cambará do } \\
\text { Sul }\end{array}$ & $\begin{array}{c}\text { Caorsi, } \\
2011\end{array}$ \\
\hline $\begin{array}{c}\text { Melanophryniscus } \\
\text { dorsalis }\end{array}$ & Amphibia & Anura & Bufonidae & EN & $\begin{array}{c}\text { Cidreira, } \\
\text { Torres e } \\
\text { Tramandai }\end{array}$ & $\begin{array}{l}\text { Lema, } \\
2011\end{array}$ \\
\hline $\begin{array}{l}\text { Melanophryniscus } \\
\text { macrogranulosus }\end{array}$ & Amphibia & Anura & Bufonidae & EN & $\begin{array}{l}\text { Maquiné e } \\
\text { Dom Pedro } \\
\text { de Alcântara }\end{array}$ & $\begin{array}{l}\text { Escobar et } \\
\text { al. } 2004\end{array}$ \\
\hline $\begin{array}{l}\text { Melanophryniscus } \\
\text { montevidensis }\end{array}$ & Amphibia & Anura & Bufonidae & EN & $\begin{array}{l}\text { Santa Vitória } \\
\text { do Palmar }\end{array}$ & $\begin{array}{c}\text { IUCN, } \\
2014\end{array}$ \\
\hline $\begin{array}{l}\text { Phyllomedusa } \\
\text { distincta }\end{array}$ & Amphibia & Anura & Hylidae & EN & $\begin{array}{c}\text { Dom Pedro } \\
\text { de } \\
\text { Alcântara, } \\
\text { São } \\
\text { Francisco de } \\
\text { Paula, Terra } \\
\text { de Areia }\end{array}$ & $\begin{array}{l}\text { Lema et al. } \\
2011\end{array}$ \\
\hline $\begin{array}{l}\text { Phyllomedusa } \\
\text { tetraploidea }\end{array}$ & Amphibia & Anura & Hylidae & EN & $\begin{array}{c}\text { Derrubadas e } \\
\text { Tenente } \\
\text { Portela }\end{array}$ & $\begin{array}{c}\text { Lema et al. } \\
2011 \\
\text { Iop et al. } \\
2011\end{array}$ \\
\hline Scinax rizibilis & Amphibia & Anura & Hylidae & $\mathrm{CR}$ & $\begin{array}{c}\text { Itati, São } \\
\text { Francisco de } \\
\text { Paula e } \\
\text { Terra de } \\
\text { Areia }\end{array}$ & $\begin{array}{l}\text { Lema et al. } \\
2011\end{array}$ \\
\hline $\begin{array}{c}\text { Sphaenorhynchus } \\
\text { caramaschii }\end{array}$ & Amphibia & Anura & Hylidae & $\mathrm{CR}$ & $\begin{array}{c}\text { Campos de } \\
\text { cima da } \\
\text { serra e litoral } \\
\text { norte }\end{array}$ & $\begin{array}{c}\text { Fonte et al. } \\
2008\end{array}$ \\
\hline Thoropa saxatilis & Amphibia & Anura & Cycloramphidae & EN & Maquiné & $\begin{array}{c}\text { Colombo, } \\
2010\end{array}$ \\
\hline
\end{tabular}

Figura 4 - Informações referentes aos anfíbios ameaçados de extinção no Rio Grande do Sul Organização: Os autores 
Referindo-se da quantificação das categorias de risco que estão os anfíbios ameaçados de extinção do Rio Grande do Sul, somente uma (Melanophryniscus cambaraensis) encontra-se na categoria Vulnerável (VU), enquanto nove espécies estão classificadas em Em Perigo (EN) e seis em Criticamente em Perigo (CR), conforme ilustrado na figura 5.

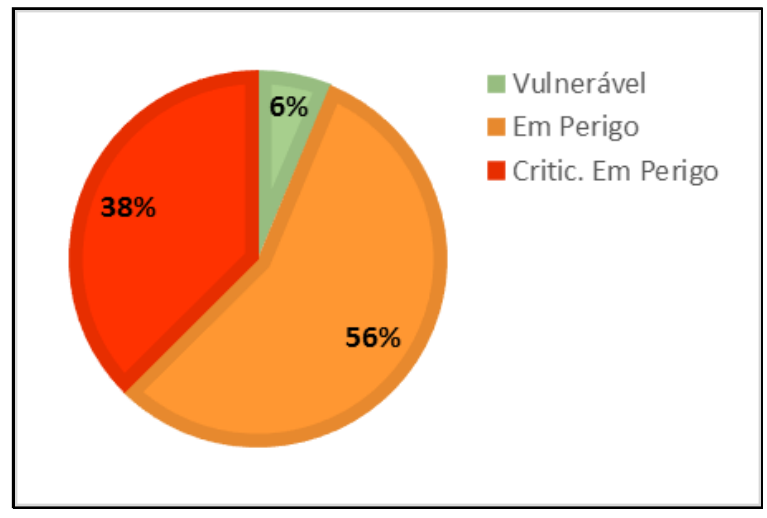

Figura 5 - Quantificação das categorias de risco dos anfíbios ameaçados de extinção no RS

Organização: Os autores

Observa-se que a categoria Em Perigo (EN) abrange a maioria dos anfíbios que encontram-se ameaçados de extinção, lembrando que ela é o segundo estado de conservação mais grave da natureza, ficando somente atrás da Criticamente em Perigo (CR), representada por seis indivíduos. Nesse sentido, ressalta-se a importância de leis ambientais que conservam as áreas naturais, preservando assim os diversos habitats das espécies.

O mapa confeccionado referente aos répteis ameaçados de extinção no estado do Rio Grande do Sul encontra-se na figura 6. Visualizando o mesmo, percebe-se que os répteis estão concentrados (com base na pesquisa realizada), próximo a Lagoa dos Patos, enquanto os outros se localizam no Planalto Meridional.

No município de Mostardas foram registradas três espécies diferentes de tartarugas, são elas: Caretta caretta (tartaruga-cabeçuda), Chelonia mydas (tartaruga-verde) e Eretmochelys imbricata (tartaruga-depente). Em Rio Grande, teve-se registro de Dermochelys coriacea (tartaruga-de-couro ou tartarugagigante). Já a Lepidochelys olivacea (tartaruga-oliva) foi identificada por pesquisadores do CERAM (Centro de Reabilitação de Animais Silvestres e Marinhos) em Balneário Pinhal (UFRGS, s/d). A lagartixa-das-dunas (Liolaemus arambarensis), cujo habitat se dá em terrenos arenosos, típicos da formação de restinga do litoral gaúcho, foi localizada nos municípios de Arambaré e São Lourenço do Sul (VERRASTRO, 2003). Por fim, em Quintão, encontrou-se o Liolaemus occipitalis, conhecido como lagartixa-da-praia, onde habita em terrenos arenosos. 

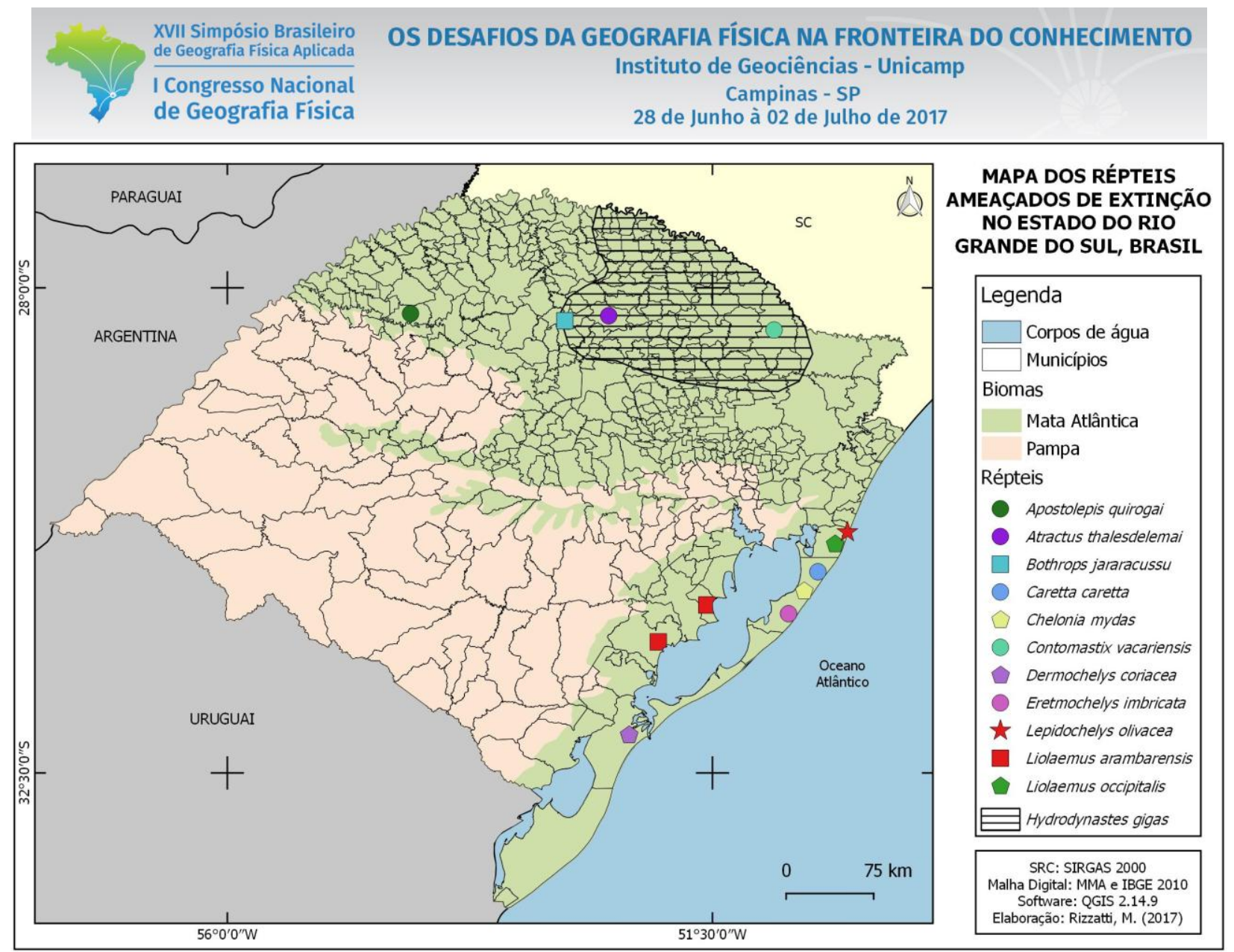

Figura 6 - Mapa dos répteis ameaçados de extinção no estado do Rio Grande do Sul

Elaboração: RIZZATTI, 2017.

Tratando-se das serpentes encontradas no planalto meridional, a Apostolepis quirogai foi identificada em Santo Ângelo, enquanto a Atractus thalesdelemai (cobra-da-terra), segundo Passos et al. (2008), localizada na Fazenda da Brigada Militar em Passo Fundo. Já Bothrops jararacuçu (jararacuçu, surucucutapete, surucucu-dourada ou urutu-dourado), cuja distribuição geográfica se dá entre $20^{\circ}$ e $26^{\circ}$ de latitude sul, abrangendo os estados de Santa Catarina, Paraná, São Paulo, Minas Gerais, Rio de Janeiro e Espirito Santo, além da Argentina, Bolívia e Paraguai, teve-se registro da mesma no Rio Grande do Sul, no município de Carazinho, conforme apontado nas pesquisas de Balestrin et al. (2002). Referindo-se a Hydrodynastes gigas (boipevaçu), a distribuição no estado se dá no planalto das araucárias.

Por fim, o lagartinho-pintado (Contomastix vacariensis), fora identificado no município de Vacaria, localizado no extremo norte do Rio Grande do Sul, que é uma espécie endêmica brasileira, cuja distribuição geográfica se dá somente na região sul. As informações referentes aos répteis ameaçados de extinção comentadas, encontram-se ilustradas na figura 7. 


\begin{tabular}{|c|c|c|c|c|c|c|}
\hline $\begin{array}{l}\text { XVII Simpósio Brasileiro } \\
\text { de Geografia Física Aplicada } \\
\text { I Congresso Nacional } \\
\text { de Geografia Física }\end{array}$ & \multicolumn{6}{|c|}{$\begin{array}{l}\text { OS DESAFIOS DA GEOGRAFIA FISICA NA FRONTEIRA } \\
\text { Instituto de Geociências - Unicamp } \\
\text { Campinas - SP } \\
28 \text { de Junho à } 02 \text { de Julho de } 2017\end{array}$} \\
\hline Nome & Classe & Ordem & Familia & Categoria & Município & Autor \\
\hline $\begin{array}{l}\text { Apostolepis } \\
\text { quirogai }\end{array}$ & Reptilia & Squamata & Dipsadidae & $\mathrm{EN}$ & $\begin{array}{c}\text { Santo } \\
\text { Ângelo }\end{array}$ & $\begin{array}{c}\text { Lema et al. } \\
2001\end{array}$ \\
\hline $\begin{array}{c}\text { Atractus } \\
\text { thalesdelemai }\end{array}$ & Reptilia & Squamata & Dipsadidae & $\mathrm{VU}$ & $\begin{array}{l}\text { Passo } \\
\text { Fundo }\end{array}$ & $\begin{array}{l}\text { Passos et } \\
\text { al. } 2005\end{array}$ \\
\hline $\begin{array}{c}\text { Bothrops } \\
\text { jararacussu }\end{array}$ & Reptilia & Squamata & Viperidae & VU & Carazinho & $\begin{array}{c}\text { Balestrin et } \\
\text { al. } 2002\end{array}$ \\
\hline Caretta caretta & Reptilia & Testudines & Cheloniidae & $\mathrm{EN}$ & Mostardas & $\begin{array}{l}\text { Domiciano } \\
\text { et al. } 2011\end{array}$ \\
\hline Chelonia mydas & Reptilia & Testudines & Cheloniidae & VU & Mostardas & $\begin{array}{c}\text { Xavier, } \\
2011\end{array}$ \\
\hline $\begin{array}{l}\text { Contomastix } \\
\text { vacariensis }\end{array}$ & Reptilia & Squamata & Teiidae & $\mathrm{EN}$ & Vacaria & $\begin{array}{c}\text { Santos, } \\
2008\end{array}$ \\
\hline $\begin{array}{c}\text { Dermochelys } \\
\text { coriacea }\end{array}$ & Reptilia & Testudines & Dermochelyidae & $\mathrm{CR}$ & $\begin{array}{c}\text { Rio } \\
\text { Grande }\end{array}$ & $\begin{array}{c}\text { Farias, } \\
2014\end{array}$ \\
\hline $\begin{array}{c}\text { Eretmochelys } \\
\text { imbricata }\end{array}$ & Reptilia & Testudines & Cheloniidae & CR & Mostardas & $\begin{array}{c}\text { Valls et al. } \\
2011\end{array}$ \\
\hline $\begin{array}{c}\text { Hydrodynastes } \\
\text { gigas }\end{array}$ & Reptilia & Squamata & Reptilia & VU & $\begin{array}{l}\text { Planalto } \\
\text { das } \\
\text { araucárias }\end{array}$ & $\begin{array}{l}\text { Iriondo et } \\
\text { a1. } 2007\end{array}$ \\
\hline $\begin{array}{c}\text { Lepidochelys } \\
\text { olivacea }\end{array}$ & Reptilia & Testudines & Cheloniidae & $\mathrm{EN}$ & $\begin{array}{c}\text { Balneário } \\
\text { Pinhal }\end{array}$ & $\begin{array}{l}\text { UFRGS, s/d } \\
\text { (CERAM) }\end{array}$ \\
\hline $\begin{array}{l}\text { Liolaemus } \\
\text { arambarensis }\end{array}$ & Reptilia & Squamata & Liolaemidae & $\mathrm{EN}$ & $\begin{array}{c}\text { Arambaré } \\
\text { e São } \\
\text { Lourenço } \\
\text { do Sul }\end{array}$ & $\begin{array}{l}\text { Corso, } \\
2011 .\end{array}$ \\
\hline $\begin{array}{l}\text { Liolaemus } \\
\text { occipitalis }\end{array}$ & Reptilia & Squamata & Liolaemidae & $\mathrm{VU}$ & $\begin{array}{c}\text { Palmares } \\
\text { do Sul }\end{array}$ & $\begin{array}{l}\text { Verrastro } \\
\text { et al. } 2003\end{array}$ \\
\hline
\end{tabular}

Figura 7 - Informações referentes aos répteis ameaçados de extinção no Rio Grande do Sul

Organização: Os autores

Referindo-se a quantificação das categorias de risco dos répteis, há uma predominância maior em Vulnerável e Em Perigo, com cinco espécies em cada uma e somente 2 espécies na categoria mais grave de conservação da natureza (Criticamente em Perigo), conforme a figura 8. Percebe-se que os répteis estão, em sua maior parte, nas categorias com menor risco, enquanto os anfíbios na de maior gravidade.

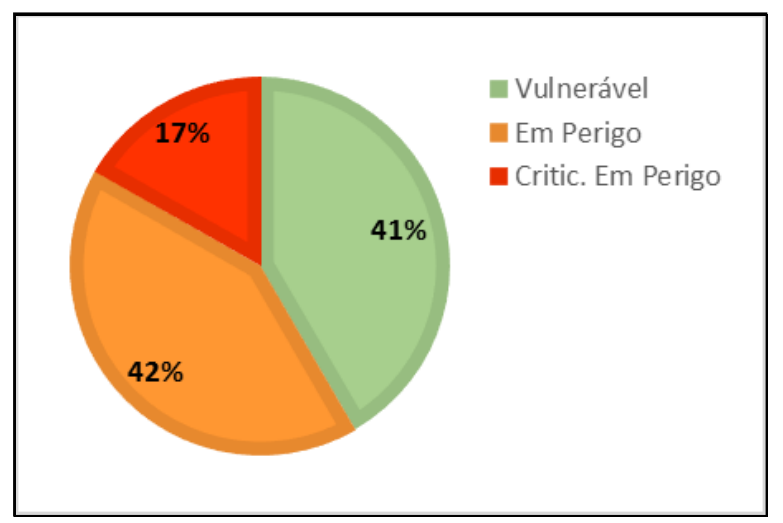

Figura 8 - Quantificação das categorias de risco dos répteis ameaçados de extinção no RS

Organização: Os autores

Observando os mapas, é possível constatar que as espécies possuem um padrão de distribuição especialmente ligado bioma da Mata Atlântica. Além disso, em relação bioma Pampa, existe somente uma 
espécie Leptodactylus labyrinthicus, localizada em Santa Maria, entretanto, a norte do município tem-se vegetação de Mata Atlântica, reconhecida pela UNESCO como Reserva da Biosfera da Mata Atlântica.

Contudo, válido salientar que o pouquíssimo número de espécies ameaçados de extinção presentes no bioma Pampa, muito provavelmente não está ligado à sua inexistência, e sim, ao pouco número de pesquisas, quando comparados com a Mata Atlântica.

O Pampa possui características estruturais menos notáveis: uma vegetação composta de gramíneas, plantas rasteiras e algumas árvores e arbustos, o que alimentou historicamente um imaginário de se tratar de uma área com pouca biodiversidade. Todavia, é exatamente o oposto a isso, pois segundo Pillar et al (2015, p. 46) nos "Campos Sulinos, há regiões com mais de 50 espécies de plantas em um único metro quadrado, e mais de 120 espécies de plantas em 100 metros quadrados".

\section{Considerações finais}

Observou-se que os anfíbios e répteis ameaçados de extinção apresentam um padrão de distribuição predominantemente ligado à Mata Atlântica, concentrando-se especialmente na região nordeste e ao litoral do Estado do Rio Grande do Sul, podendo ser atribuído ao número de pesquisadores da Mata Atlântica ser maior do que o Pampa, talvez pela grande quantidade de lagoas/lagunas presentes na faixa litorânea do território gaúcho, além de ser classificada como um hotspot de biodiversidade.

Com relação às categorias de ameaça de extinção, a saber, Vulnerável (VU), Em Perigo (EN) e Criticamente em Perigo (CR), há uma predominância na classe Em Perigo, fato que reflete o descuido com os ecossistemas e põem em alerta pesquisadores, legisladores e a sociedade como um todo quanto ao risco de desaparecimento de espécies no Rio Grande do Sul. O descuido e o descaso com os biomas são uma característica marcante da crise ambiental, que venera o mercado e não valoriza o patrimônio natural das diversas áreas do Planeta.

E por último, porém de importância fundamental, diz respeito a ação dos Estados para com a questão ambiental, sobretudo o Estado do Rio Grande do Sul, que recentemente optou, em uma infeliz ironia de palavras, pela extinção de diversas fundações estatais, entre elas a Fundação Zoobotânica (FZB), esta que forneceu os dados contidos nesse artigo. 


\section{Bibliografia}

BALESTRIN, R. L.; LEITÃO-DE-ARAUJO, M.; ALVES, M. L. M. Ocorrência de híbridos não naturais entre Bothrops jararaca e B. neuwiedi (Serpentes, Viperidae). Iheringia, v. 92, p. 85-90, 2002.

ESCOBAR, A.; MANEYRO, R.; DI-BERNARDO, M. Rediscovery of Melanophryniscus macrogranulosus (Anura, Bufonidae), an endangered species of Amphibia from the state of Rio Grande do Sul, Brazil. In: BIOCIÊNCIAS, Porto Alegre, v. 12, n. 1, p. 57-58, jun. 2004.

FONTE, L. F. M. D., SANTOS, R. R., COLOMBO, P., ZANK, C., \& VOLKMER, G. Status taxonômico de sphaenorhynchus aff. Surdus (anura: hylidae) dos campos de cima da serra, Rio Grande do Sul e Santa Catarina. Salão de Iniciação Científica. Livro de resumos. Porto Alegre: UFRGS, 2008.

FUNDAÇÃO ZOOBOTÂNICA DO RIO GRANDE DO SUL (FZB/RS). Táxons da fauna silvestre do Rio Grande do Sul ameaçados de extinção no estado (categorias CR - Criticamente em Perigo, EN - Em Perigo e VU - Vulnerável), 2014. Disponível em: < http://www.fzb.rs.gov.br/upload/201409091158080 9_09_2014_especies_ameacadas.pdf >. Acesso em: 06 Jan. de 2017.

HASENACK, H.; WEBER, E.(org.) Base cartográfica vetorial contínua do Rio Grande do Sul - escala 1:50.000. Porto Alegre: UFRGS Centro de Ecologia. 2010.

IBGE. Bases cartográficas: malhas digitais - arquivos vetoriais de municípios por unidade de federação, 2010.

IBGE. Mapa de Biomas do Brasil, primeira aproximação. Rio de Janeiro: IBGE, 2004.

IUCN. IUCN Red List Categories and Criteria: Version 3.1. IUCN Species Survival Commission. IUCN, Gland, Switzerland and Cambridge, UK, 2001. Disponível em: < http://s3.amazonaws.com/iucnredlistnewcms/staging/public/attachments/3108/redlist_cats_crit_en.pdf >. Acesso em: 04 Jan. 2017.

LEMA, T. de; MARTINS, L. A. Anfíbios do Rio Grande do Sul: catálogo, diagnoses, distribuição, iconografia. Dados eletrônicos - Porto Alegre: EDIPUCRS, 2011.

LEWINSOHN, T. M., PRADO, P.I. Sintese do conhecimento atual da biodiversidade brasileira, p. 21-109. In: T.M. Lewinsohn (coord.) Avaliação do estado do conhecimento da biodiversidade brasileira. Vol. 1. Brasília, Ministério do Meio Ambiente. (Série Biodiversidade, 15), 2006.

MACHADO, A. B. M; DRUMMOND, G. M.; PAGLIA, A. P.. Livro vermelho da fauna brasileira ameaçada de extinção. MMA; Fundação Biodiversitas, 2008.

PASSOS, P., FERNANDES, R.; ZANELLA, N. Atractus thalesdelemai - The Reptile Database, 2005. Disponível em: < http://reptile-database.reptarium.cz/species?genus=Atractus\&species=thalesdelemai $>$. Acesso em: Jan. 2017.

PILLAR, V.; LANGE, O. Os Campos do Sul. Porto Alegre: Rede Campos Sulinos - UFRGS, 2015.

PONTES, R. C. Avalição fitogeográfica dos relictos xerófitos em afloramentos rochosos na localidade do Campestre do Divino, Santa Maria - RS. Dissertação (Mestrado). Universidade Federal de Santa Maria, Centro de Ciências Naturais e Exatas, Programa de Pós-Graduação em Geografia e Geociências, 2017.

RIZZATTI, M.; FIGUEIRÓ, A. S.; COSTA, I. T.; SPODE, P. L. C.. Mapeamento dos Invertebrados Ameaçados de Extinção no Estado do Rio Grande do Sul, Brasil. In: I Congresso Internacional do Pampa, 2016, Santa Maria. Anais do I Congresso Internacional do Pampa, 2016.

ROMA, J. C. Mapa de cobertura vegetal dos biomas brasileiros. Ministério do Meio Ambiente, Brasil, 2007. Disponível em: http://mapas.mma.gov.br/mapas/aplic/probio/datadownload.htm?/mata_atlantica/mapas_pdf/cartas_ imagem/250000/ >. Acesso em: 02 Jan. 2017.

UFRGS. Centro de Reabilitação de Animais Silvestres e Marinhos - Você conhece as tartarugas-marinhas do nosso litoral? Disponível em: 〈http://www.ufrgs.br/ceclimar/ceram/fauna-marinha-e-costeira/tartarugas-marinhas〉. Acesso em: 15 Jan. 2017.

VERRASTRO, L., VERONESE, L., BUJES, C. S.; DIAS-FILHO, M. M. A new species of Liolaemus from southern Brazil (Iguania, Tropiduridae). In: Herpetologica, v. 59, n. 1, p. 105-118, 2003. 